\title{
Acidic and cesium salts of polyoxometalates with and without vanadium supported on MCM-41 as catalysts for oxidation of cyclohexane with $\mathrm{H}_{2} \mathrm{O}_{2}$
}

\author{
W. Trakarnpruk $\cdot$ J. Jatupisarnpong
}

Received: 6 September 2012/Accepted: 21 November 2012/Published online: 25 January 2013

(C) The Author(s) 2013. This article is published with open access at Springerlink.com

\begin{abstract}
Acidic and cesium salts of polyoxometalate (POM) with and without vanadium supported on MCM-41 were synthesized and their catalytic activities were investigated in the oxidation of cyclohexane with $\mathrm{H}_{2} \mathrm{O}_{2}$ under solvent-free condition. The products are cyclohexanol and cyclohexanone. The catalytic activity order is: $\mathrm{CsV}$ $\mathrm{POM} / \mathrm{MCM}>\mathrm{HVPOM} / \mathrm{MCM}>\mathrm{CsPOM} / \mathrm{MCM} \sim \mathrm{HPOM} /$ $\mathrm{MCM}>\mathrm{CsVPOM}>\mathrm{CsPOM}$ catalysts. High conversion and selectivity to cyclohexanone over the supported catalysts are due to redox property and high surface area. These heterogeneous catalysts can be reused.
\end{abstract}

Keywords Polyoxometalate - Oxidation · Cyclohexane · Hydrogen peroxide

\section{Introduction}

Selective oxidation of cyclohexane yields cyclohexanol and cyclohexanone, important intermediates in the production of adipic acid and caprolactam, in the manufacture of nylon-6 and nylon-66 polymers [1]. Polyoxometalates (POMs) have been used as catalysts in various reactions, e.g. oxidation of organic compounds due to the variety of their compositions, sizes, shapes, redox potentials, acidity, and solubility [2-4]. Most of the homogeneous oxidation of cyclohexane catalyzed by polyoxometalates (POMs) was performed in acetonitrile solvent with $\mathrm{H}_{2} \mathrm{O}_{2}$, e.g. tetrabutylammonium salts of $\left[\mathrm{XW}_{11} \mathrm{O}_{39}\right]^{n-}$ and $\left[\mathrm{XW}_{11} \mathrm{MO}_{39}\right]^{(n-m)-}(\mathrm{X}=\mathrm{P}, \mathrm{Si}, \mathrm{B}$ and

W. Trakarnpruk $(\bowtie) \cdot$ J. Jatupisarnpong Department of Chemistry, Petrochemistry and Polymer Science, Faculty of Science, Chulalongkorn University, Bangkok 10330, Thailand

e-mail: wimonrat.t@chula.ac.th
$\left.\mathrm{M}^{\mathrm{III}}=\mathrm{Fe}, \mathrm{Mn}\right),[5],\left[\mathrm{M}_{4}\left(\mathrm{H}_{2} \mathrm{O}\right)_{2}\left(\mathrm{PW}_{9} \mathrm{O}_{34}\right)_{2}\right]^{10-}, \mathrm{M}^{\mathrm{II}}=\mathrm{Co}$, $\mathrm{Mn}$ and $\mathrm{M}^{\mathrm{III}}=\mathrm{Fe}$ where $\left[\mathrm{Fe}_{4}\left(\mathrm{H}_{2} \mathrm{O}\right)_{2}\left(\mathrm{PW}_{9} \mathrm{O}_{34}\right)_{2}\right]^{6-}$ showed higher conversion of cyclohexane but the main product was cyclohexyl hydroperoxide [6]. Heteropolytungstic acid or HPW supported on MCM-41 [7-10] finds its place in catalysis over many organic reactions owing to the typical characteristics of the mesoporous materials of the MCM-41 type with highly ordered mesoporosity (pore size 2-10 nm) [11], large surface area, and high hydrothermal stability and acidity, making these materials as efficient catalysts in the synthesis and conversion of organic molecules. Transition metal-incorporated MCM-41 was used as catalyst for the oxidation of cyclohexane in the presence of solvent and $\mathrm{H}_{2} \mathrm{O}_{2}$ or tert-butyl hydroperoxide [12]. Ce-MCM-41 gave high selectivity to cyclohexanol in acetic acid as solvent and $\mathrm{H}_{2} \mathrm{O}_{2}$ as oxidant [13]. $\mathrm{CeO}_{2} / \mathrm{V}$-HMS using $\mathrm{O}_{2}$ as oxidant exhibited $17.8 \%$ conversion of cyclohexane but low selectivity to cyclohexanone (38\%) [14].

It has been reported that substitution of $\mathrm{Cs}^{+}$for $\mathrm{H}^{+}$in $\mathrm{Cs}_{\mathrm{x}} \mathrm{H}_{3-\mathrm{x}} \mathrm{PW}_{12} \mathrm{O}_{40}$ catalysts improved surface area and thermal stability compared to parent acids, the surface area is the largest when $x=2.5$ [15]. A problem associated with the use of these Cs catalysts is that the salt particles disperse as a colloid in water and organic solvents, making it difficult to separate the salt from the reaction products by simple filtration [16]. Therefore they were supported on a carrier [17]. The POMs of the Keggin structure have molecular diameter of around $1.2 \mathrm{~nm}$; it is therefore feasible to insert into the MCM-41 [18]. Introduction of vanadium into heteropolyacid improved the catalytic activity in oxidation due to its redox property $[19,20]$. We have previously reported the catalytic activity of the tetrabutylammonium transition metalsubstituted polyoxometalates supported on MCM-41 prepared by incipient wetness impregnation method and 
found that the activity increased in the order $\mathrm{V}>\mathrm{Cu}>\mathrm{Co}>\mathrm{Fe}[21]$.

The aim of this work was to study the oxidation of cyclohexane with $\mathrm{H}_{2} \mathrm{O}_{2}$ over acidic and cesium salts of polyoxometalates (with and without vanadium) supported on MCM-41. Hydrogen peroxide is the oxidant of choice as it is inexpensive, easily available, easy to handle and gives only water and oxygen as the products of decomposition.

\section{Experimental}

Materials

$\mathrm{H}_{3} \mathrm{PW}_{12} \mathrm{O}_{40}$ (Wako Pure Chemical), $\mathrm{Cs}_{2} \mathrm{CO}_{3}$ (Fluka), $\mathrm{Na}_{2} \mathrm{WO}_{4} \cdot 2 \mathrm{H}_{2} \mathrm{O}, \quad \mathrm{Na}_{2} \mathrm{HPO}_{4}, \quad \mathrm{NaVO}_{3}$ and oxalic acid (Sigma-Aldrich), $\mathrm{H}_{2} \mathrm{O}_{2}$ (30 wt $\%$ aqueous), cyclohexane (Merck), aqueous $\mathrm{NH}_{3}$ (32\%, Merck), tetraethylorthosilicate (TEOS), cetyltrimethylammonium bromide (CTAB, $98 \%$, Fine Chem.) and triblock poly(ethylene oxide)poly(propylene oxide)-poly(ethylene oxide) copolymer or P123 ( $M=5,800)$ (Fluka) were used as received.

Catalysts preparation

MCM-41 [22]

CTAB and ammonia were dissolved in water at room temperature and then TEOS was added dropwise into the solution under stirring $(300 \mathrm{rpm})$. The composition of $\mathrm{SiO}_{2}: \mathrm{CTAB}: \mathrm{NH}_{4} \mathrm{OH}: \mathrm{H}_{2} \mathrm{O}$ was 1.0:0.12:8:114 (or $26 \mathrm{ml}$ : $5 \mathrm{~g}: 57 \mathrm{ml}: 235 \mathrm{~g}$ ). After $2 \mathrm{~h}$ stirring, a gel was obtained. The gel was transferred into a Teflon bottle that was then heated at $110{ }^{\circ} \mathrm{C}$ for $96 \mathrm{~h}$. The solid product was recovered by filtration, washed with deionized water until the filtrate was neutral, and finally dried. The removal of template was performed by refluxing the as-synthesized product in a mixture of methanol and $\mathrm{HCl}$. The final product was separated, washed with methanol and dried.

$\mathrm{H}_{4} \mathrm{PVW}{ }_{11} \mathrm{O}_{40}[23]$

$10 \mathrm{~g}$ of $\mathrm{NaVO}_{3}$ (dissolved in $100 \mathrm{ml}$ of oxalic acid) and $6 \mathrm{~g}$ of $\mathrm{Na}_{2} \mathrm{HPO}_{4}$ (dissolved in $100 \mathrm{ml}$ of distilled water) were mixed. $100 \mathrm{~g}$ of $\mathrm{Na}_{2} \mathrm{WO}_{4} \cdot 2 \mathrm{H}_{2} \mathrm{O}$ (dissolved in $150 \mathrm{ml}$ of distilled water) was added, then the mixed solution was heated to $80{ }^{\circ} \mathrm{C}$ and then $60 \mathrm{ml}$ of $\mathrm{H}_{2} \mathrm{SO}_{4}$ was slowly added to the solution. The solution was stirred for $8 \mathrm{~h}$. After cooling the solution to room temperature, it was extracted with diethyl ether. The solvent was evaporated to obtain a solid product which was washed with distilled water and dried.
Cs salt of polyoxometalates

Cs salts of POM were prepared by adding the $\mathrm{Cs}_{2} \mathrm{CO}_{3}$ solution $(0.47 \mathrm{M})$ dropwise to the $\mathrm{H}_{3} \mathrm{PW}_{12} \mathrm{O}_{40}$ or $\mathrm{H}_{4} \mathrm{PVW}_{11} \mathrm{O}_{40}$ solution $(0.75 \mathrm{M})$ according to the literature [24]. The precipitate obtained was aged for $20 \mathrm{~h}$ at room temperature, then dried at $110{ }^{\circ} \mathrm{C}$ and calcined at $300{ }^{\circ} \mathrm{C}$ for $3 \mathrm{~h}$. The products are denoted as CsPOM and CsVPOM, respectively. Their chemical compositions were characterized by ICP and XRF.

\section{Cs salt of polyoxometalates supported on MCM-41}

Cs salts of POM supported on MCM-41 were prepared by a two-step impregnation method [25] as the Cs salts of POM are not soluble in water and alcohol. First MCM-41 (2 g) was impregnated with $\mathrm{Cs}_{2} \mathrm{CO}_{3}(80 \mathrm{mg}, 0.25 \mathrm{mmol})$ solution and the mixture was stirred for $12 \mathrm{~h}$, then evaporated to dryness at $110{ }^{\circ} \mathrm{C}$ and calcined at $300{ }^{\circ} \mathrm{C}$ for $2 \mathrm{~h}$. Then $\mathrm{H}_{3} \mathrm{PW}_{12} \mathrm{O}_{40}$ or $\mathrm{H}_{4} \mathrm{PVW}_{11} \mathrm{O}_{40}(15$ and $20 \mathrm{wt} \%)$ was impregnated by the incipient wetness impregnation, using 1-butanol as a solvent to obtain CsPOM/MCM or CsVPOM/MCM, respectively. The resulting solids were dried and calcined at $350{ }^{\circ} \mathrm{C}$ for $3 \mathrm{~h}$ in air. For comparison, $\mathrm{H}_{3} \mathrm{PW}_{12} \mathrm{O}_{40} / \mathrm{MCM}-41$ (HPOM/MCM) and $\mathrm{H}_{4} \mathrm{PVW}_{11} \mathrm{O}_{40} /$ MCM-41 (HVPOM/MCM) with $20 \%$ loading were prepared by incipient wetness impregnation method and calcined at $350{ }^{\circ} \mathrm{C}$ for $3 \mathrm{~h}$ in air. Percentages of $\mathrm{Cs}$ and $\mathrm{W}$ were determined by ICP.

\section{Catalyst characterization}

Specific surface area and pore volume were measured using BET method on a BELSORP-mini. The samples were degassed at $250{ }^{\circ} \mathrm{C}$ for $4 \mathrm{~h}$.

XRD measurements were performed on Rigaku, DMAX 2002/Ultima Plus powder X-ray diffractometer with a monochromatic $\mathrm{Cu} \mathrm{K} \alpha$ radiation.

The infrared spectra were obtained on a Nicolet FT-IR Impact 410 spectrophotometer with a pressed $\mathrm{KBr}$ pellet in the range of $3,000-400 \mathrm{~cm}^{-1}$.

The $\mathrm{NH}_{3}$-TPD of the samples was carried out in a CHEMBET-3000 (Quantachrome, USA) instrument. About $0.1 \mathrm{~g}$ powdered sample was taken inside a quartz $\mathrm{U}$ tube and degassed at $350{ }^{\circ} \mathrm{C}$ for $1 \mathrm{~h}$ with $\mathrm{N}_{2}$ flow. The sample was then cooled to $30^{\circ} \mathrm{C}$ and the gas flow was changed to $\mathrm{NH}_{3}$ for $30 \mathrm{~min}$. The $\mathrm{NH}_{3}$-adsorbed sample was then purged with $\mathrm{N}_{2}$ to remove any weakly adsorbed $\mathrm{NH}_{3}$ on the catalyst surface. It was then heated under $\mathrm{N}_{2}$ flow at a heating of $10^{\circ} \mathrm{C} / \mathrm{min}$ to record the spectra.

FT-IR spectra of adsorbed pyridine were also recorded to evaluate the acidic sites of the samples. The adsorption of pyridine was performed at $100{ }^{\circ} \mathrm{C}$ to avoid the influence 
of physisorption, and then the sample was evacuated at the same temperature for $30 \mathrm{~min}$.

The amounts of $\mathrm{Cs}, \mathrm{V}$ and $\mathrm{W}$ were analyzed by inductively coupled plasma emission (ICP, Perkin Elmer model PLASMA-1000). The P content was determined on ARL 8410 X-ray fluorescence spectrometer (XRF).

${ }^{31} \mathrm{P}$ MAS NMR experiments were performed with a Varian Mercury Plus NMR spectrometer operating at 121.4 $\mathrm{MHz}$ at ambient temperature using a $7 \mathrm{~mm}$ Varian CP/MAS probe and silicon nitride rotors and the samples were spun at a rate of $5 \mathrm{kHz}$. The spectra were referenced to $\mathrm{H}_{3} \mathrm{PO}_{4}$.

\section{Oxidation of cyclohexane}

Cyclohexane, catalyst and aqueous $\mathrm{H}_{2} \mathrm{O}_{2}(30 \%)$ were added into a $60 \mathrm{ml}$ Parr reactor. The reaction mixture was heated to $80{ }^{\circ} \mathrm{C}$ and stirred for $8 \mathrm{~h}$. The catalyst was separated by filtration and the products were extracted with diethyl ether and dried, analyzed by GC [chromatograph Varian CP-3800 GC; CP-Sil (30 m × $0.25 \mathrm{~mm})$ column].

\section{Results and discussion}

From the elemental analysis of the synthesized CsPOM and CsVPOM the analyzed percentages of elements can be matched with the chemical formula of $\mathrm{H}_{0.5} \mathrm{Cs}_{2.5} \mathrm{PW}_{12} \mathrm{O}_{40}$ and $\mathrm{H}_{2} \mathrm{Cs}_{2} \mathrm{PVW}_{11} \mathrm{O}_{40}$. CsPOM, anal (\%): Cs, 10.62; W, 67.45; P, 0.92; calc (\%): Cs, 10.76; W, 68.41; P, 0.96 and CsVPOM, anal (\%): Cs, 11.10; W, 86.90; P, 1.17; V, 2.02; calc (\%): Cs, 11.65; W, 84.82; P, 1.30; V, 2.14.

Surface area and pore volume of the catalysts are shown in Table 1. The introduction of large countercations such as $\mathrm{Cs}^{+}$into a heteropoly compound to replace the small $\mathrm{H}^{+}$ increases specific surface areas of the CsPOM, resulted in the formation of micropores and mesopores. After loading with POM the reduction in the surface area and pore volume could be due to deposition of POM inside the mesochannels or dispersion on the surface of the MCM-41 support. Both surface area and pore volume decreased with increasing loading of POM. This is due to the inclusion of POM into the pore of one-dimensional mesopores of MCM-41 or by the agglomeration of POM on the external surface of the support. Table 1 also showed percentages of POM in the supported samples deduced from the chemical analysis of W content by ICP technique; they are close to the loaded values. The Cs:W mole ratios were calculated from percentages of analyzed $\mathrm{Cs}$ and $\mathrm{W}$ of both unsupported and supported catalysts. It was found that in the supported catalysts, Cs:W mole ratio decreased when increasing the percentage of loading of POM.

The $\mathrm{N}_{2}$ adsorption-desorption isotherms of the samples are shown in Fig. 1. MCM-41 and the supported catalysts show a type IV isotherm according to IUPAC classification, given by mesoporous materials.

The total acidity of the catalysts was measured by temperature programmed desorption of ammonia $\left(\mathrm{NH}_{3}-\right.$ TPD) and tabulated in Table $1 . \mathrm{NH}_{3}$-TPD spectra of MCM, HPOM/MCM and CsPOM/MCM (not shown) reveal that the MCM-41 was weakly acidic due to surface $\mathrm{Si}-\mathrm{OH}$. It showed a broad peak about $100-300{ }^{\circ} \mathrm{C}$. When these silanol groups were replaced with stronger acidic sites of HPOM the acidity increased. For the HVPOM/MCM when $\mathrm{W}$ atoms were partly substituted by $\mathrm{V}$ atoms, the acidity decreased. In case of the CsPOM/MCM, the acidity also decreased with substitution of $\mathrm{Cs}$ ion for protons [26]. However, the acidity of the CsPOM/MCM was higher than that of the unsupported CsPOM, as previously reported [27]. Compared between the HPOM/MCM and CsPOM/ MCM, the acidity of the CsPOM/MCM was lower but not much, because it possessed high surface acidity.

Table 1 Characteristics of catalysts

\begin{tabular}{|c|c|c|c|c|c|c|}
\hline \multirow[t]{2}{*}{ Catalyst } & \multicolumn{2}{|l|}{$\%$ POM } & \multirow[t]{2}{*}{$\mathrm{Cs}: \mathrm{W}^{\mathrm{b}}$ mole ratio } & \multirow[t]{2}{*}{$\mathrm{S}_{\mathrm{BET}}\left(\mathrm{m}^{2} / \mathrm{g}\right)$} & \multirow[t]{2}{*}{$\mathrm{V}_{\text {pore }}\left(\mathrm{cm}^{3} / \mathrm{g}\right)$} & \multirow[t]{2}{*}{ Acidity $(\mathrm{mmol} / \mathrm{g})$} \\
\hline & Loaded & Analyzed $^{\mathrm{a}}$ & & & & \\
\hline $\mathrm{MCM}$ & - & - & - & 980 & 0.85 & 0.13 \\
\hline CsPOM & - & - & $2.5: 12$ & 125 & 0.07 & 29.4 \\
\hline CsVPOM & - & - & $2.0: 12$ & 120 & 0.07 & 24.8 \\
\hline \multirow[t]{2}{*}{ CsPOM/MCM } & 15 & 14.8 & $1.7: 12$ & 745 & 0.68 & 32.4 \\
\hline & 20 & 19.4 & $1.2: 12$ & 696 & 0.60 & 36.1 \\
\hline \multirow[t]{2}{*}{ CsVPOM/MCM } & 15 & 14.7 & $1.9: 12$ & 765 & 0.67 & 28.6 \\
\hline & 20 & 19.6 & $1.2: 12$ & 700 & 0.62 & 32.5 \\
\hline HPOM/MCM & 20 & 19.5 & - & 677 & 0.71 & 40.3 \\
\hline HVPOM/MCM & 20 & 19.7 & - & 668 & 0.68 & 37.9 \\
\hline
\end{tabular}

${ }^{a}$ Deduced from the chemical analysis of $\mathrm{W}$ by ICP

b Deduced from the chemical analysis of Cs and W by ICP 

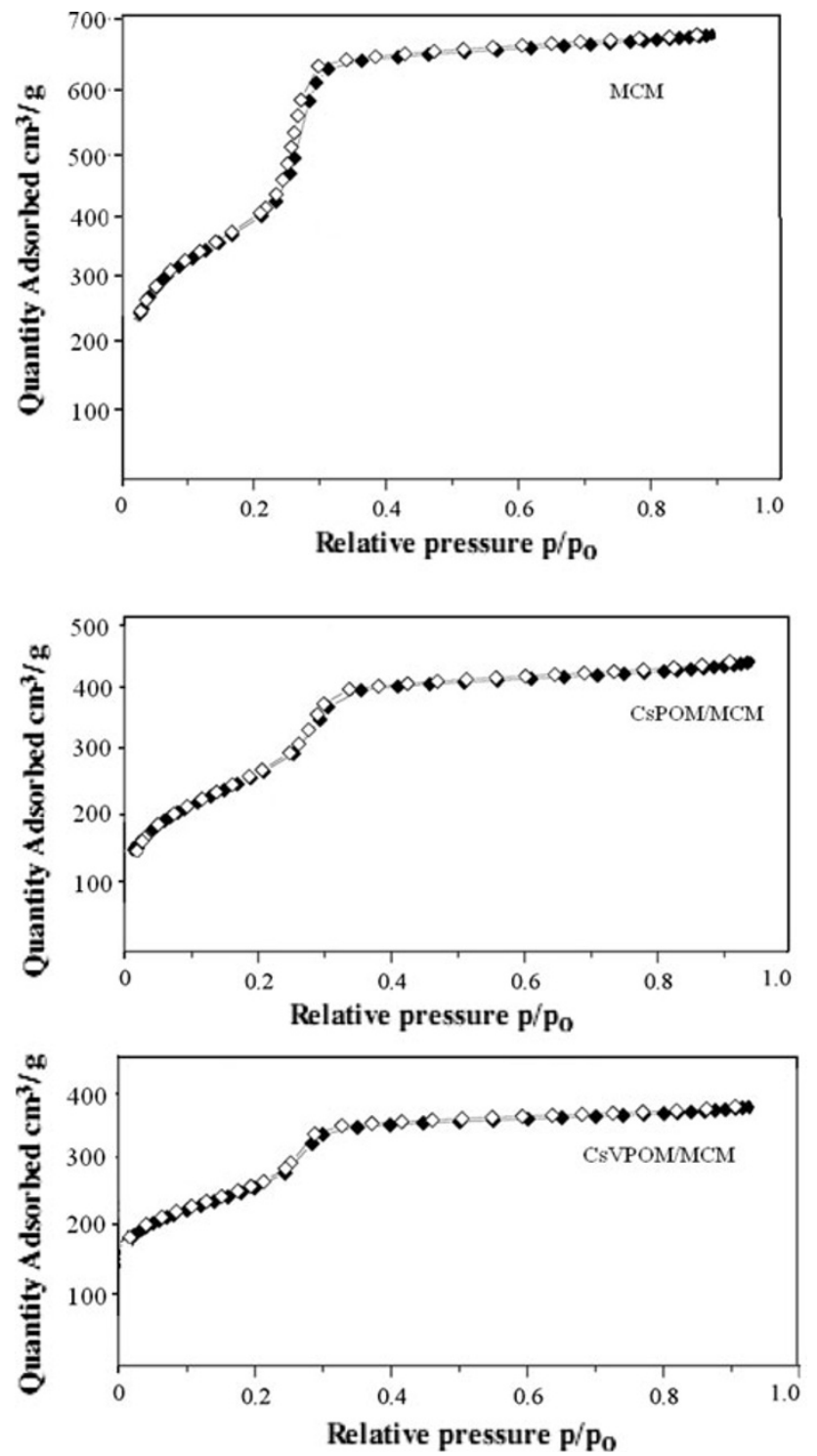

Fig. $1 \mathrm{~N}_{2}$ adsorption-desorption isotherms of MCM-41, CsPOM/ $\mathrm{MCM}$ and CsVPOM/MCM

To discriminate the type of acid sites of the supported catalysts, pyridine adsorbed FT-IR spectra of HPOM/MCM and $\mathrm{CsPOM} / \mathrm{MCM}$ samples were taken. The spectra are presented in Fig. 2. A peak at $1,445 \mathrm{~cm}^{-1}$ is due to the pyridine adsorbed on Lewis acid sites (L), a peak at $1,545 \mathrm{~cm}^{-1}$ is due to adsorption on Bronsted acid sites (B) and a peak around $1,493 \mathrm{~cm}^{-1}$ is due to both Bronsted and Lewis acid sites [28]. The HPOM/MCM showed strong Bronsted acidity, higher Bronsted acid sites peak than Lewis acid sites peak. The CsPOM/MCM showed increased Lewis acidity.

In Fig. 3, the XRD pattern of the MCM-41 exhibits the ordered hexagonal structure, showing a strong peak at $2 \theta=2.2^{\circ}$ due to (100) plane and small peaks due to (110) and (200) plane reflections within $5^{\circ}$. The XRD patterns of

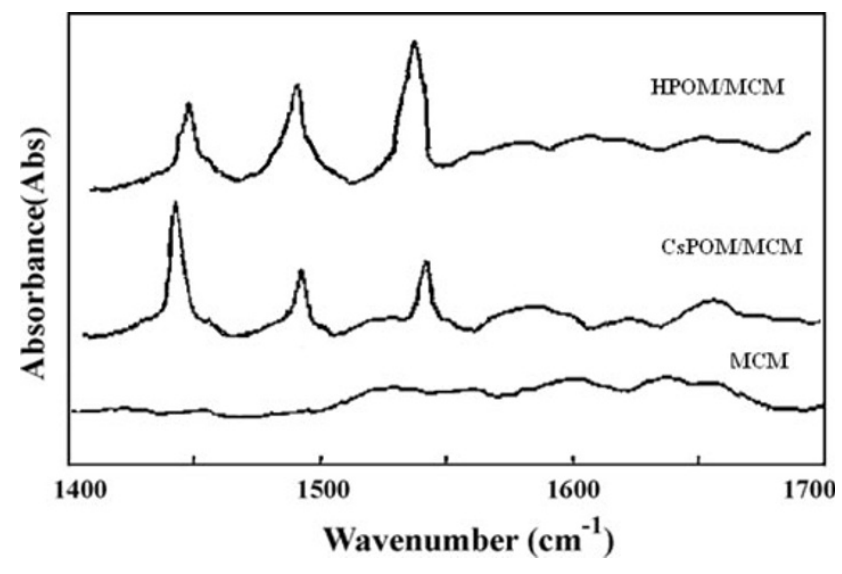

Fig. 2 IR spectra of adsorbed pyridine on the HPOM/MCM and $\mathrm{CsPOM} / \mathrm{MCM}$
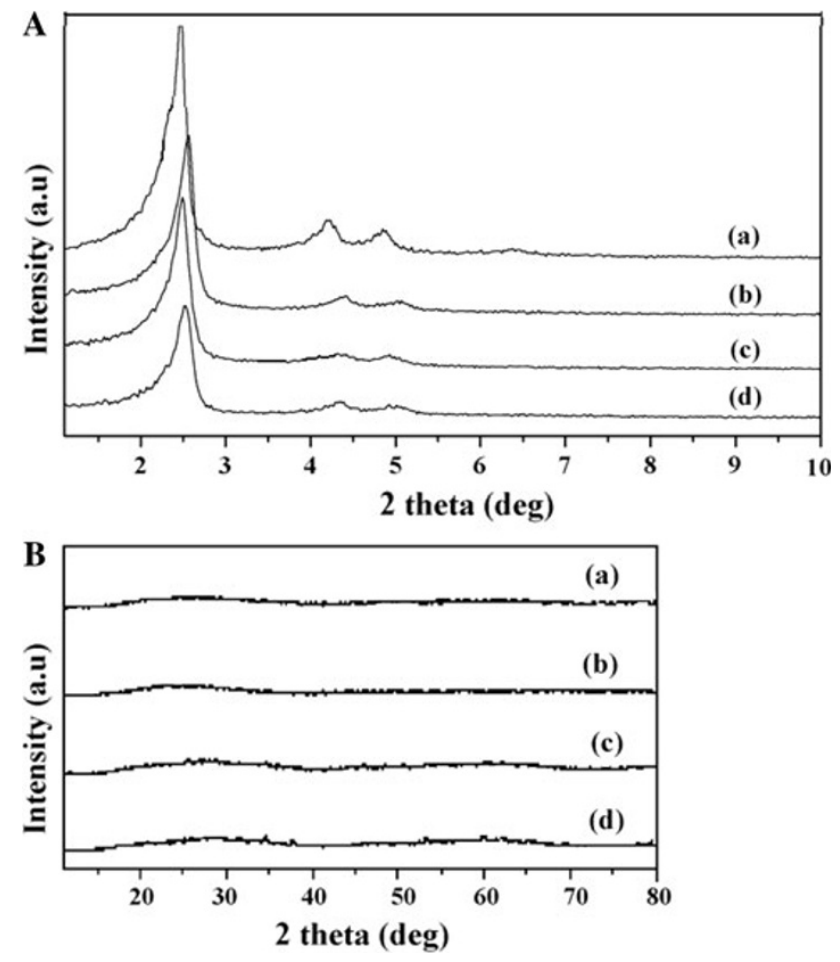

Fig. 3 Low and wide angle (A and B) XRD patterns of a MCM, $b$ CsPOM/MCM, $c$ CsVPOM/MCM and $d$ HVPOM/MCM

acidic and cesium POMs supported on MCM-41 still illustrate the characteristics of a typical mesoporous MCM41 structure but with decreased intensity. This may indicate a structural distortion of the MCM-41 or more simply a reduction of its long range order. The absence of peaks belonging to crystalline POM at the high angles (compared to the XRD patterns of the HPOM and CsPOM without support shown in Fig. 4) indicated that POM is finely dispersed on the MCM-41 support or was due to low loadings (15-20\%). This result is not surprising since the 


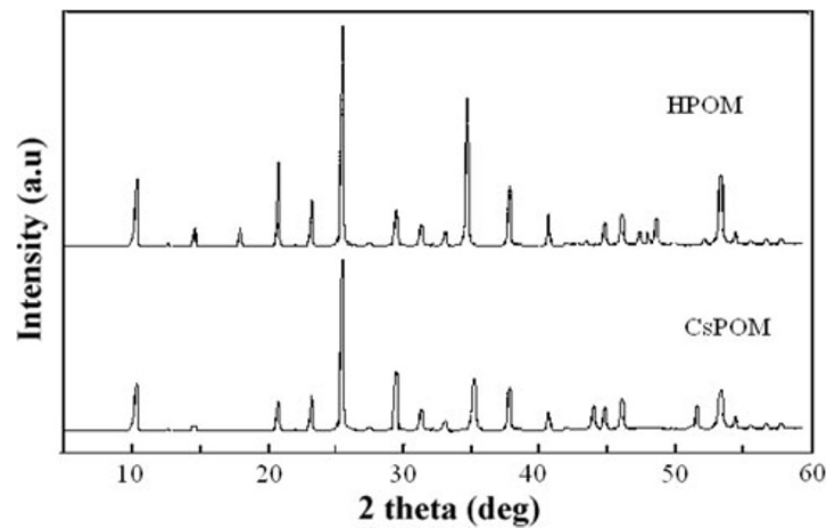

Fig. 4 XRD patterns of HPOM and CsPOM

MCM-41 has a pore size higher than POM crystals $(1.2 \mathrm{~nm})$ [29]. However, with higher loadings (above $60 \%$ ), it was reported that the reflections from the POM can be observed [10].

FT-IR spectra in the range of $400-2,200 \mathrm{~cm}^{-1}$ of HPOM and HPOM supported on MCM-41 are shown in Fig. 5. The characteristic FT-IR bands at 1,078, 985, 880 and $788 \mathrm{~cm}^{-1}$ are attributed to $\mathrm{P}-\mathrm{O}$, terminal bond (W-O), corner-sharing $\mathrm{W}-\mathrm{O}-\mathrm{W}$ and edge-sharing $\mathrm{W}-\mathrm{O}-\mathrm{W}$, respectively. When the HPOM was supported on the MCM-41, these bands overlap with the framework bands of the MCM-41 in the same region. However, a tiny band can be seen at $882 \mathrm{~cm}^{-1}$.

Figure 6 shows FT-IR spectra of CsPOM and CsPOM/ MCM. The characteristic FT-IR bands of CsPOM at 1,080, 985,890 and $800 \mathrm{~cm}^{-1}$ are attributed to $\mathrm{P}-\mathrm{O}$, terminal bond $(\mathrm{W}-\mathrm{O})$, corner-sharing $\mathrm{W}-\mathrm{O}-\mathrm{W}$ and edge-sharing $\mathrm{W}-\mathrm{O}-\mathrm{W}$, respectively [24]. In the CsPOM/MCM, an

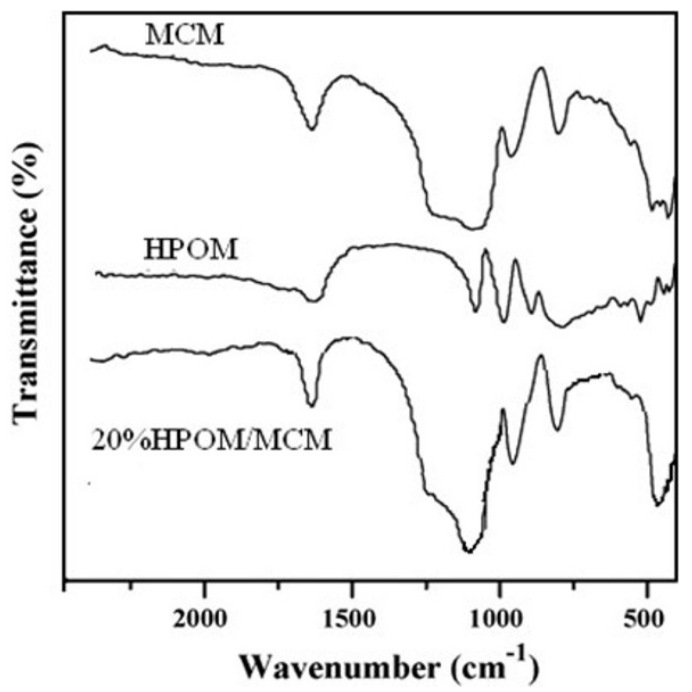

Fig. 5 FT-IR spectra of MCM, HPOM and $20 \%$ HPOM/MCM

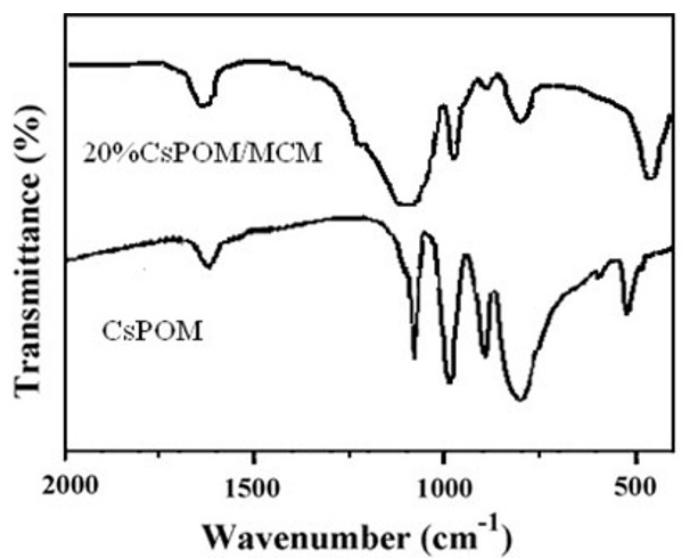

Fig. 6 FT-IR spectra of CsPOM and $20 \%$ CsPOM/MCM

observed band at $889 \mathrm{~cm}^{-1}$ reveals that presence of CsPOM in the supported catalyst, as reported in the literature [27]. The FT-IR spectrum of the CsVPOM/MCM (not shown) was similar to that of the CsPOM/MCM.

Insight into the state of HPOM in the supported catalysts can be gained by ${ }^{31} \mathrm{P}\left\{{ }^{1} \mathrm{H}\right\}$ MAS NMR. As shown in Fig. 7, the HPOM exhibited a sharp resonance at $-15.1 \mathrm{ppm}$ [29], corresponding to the tetrahedral coordination of $\mathrm{PO}_{4}$ in Keggin unit. The HPOM/MCM showed a strong peak at $-15.4 \mathrm{ppm}$ indicating that the Keggin structure of the HPW is retained after supporting in the MCM- 41 . The shift of peak is due to the interaction of HPOM with MCM-41,

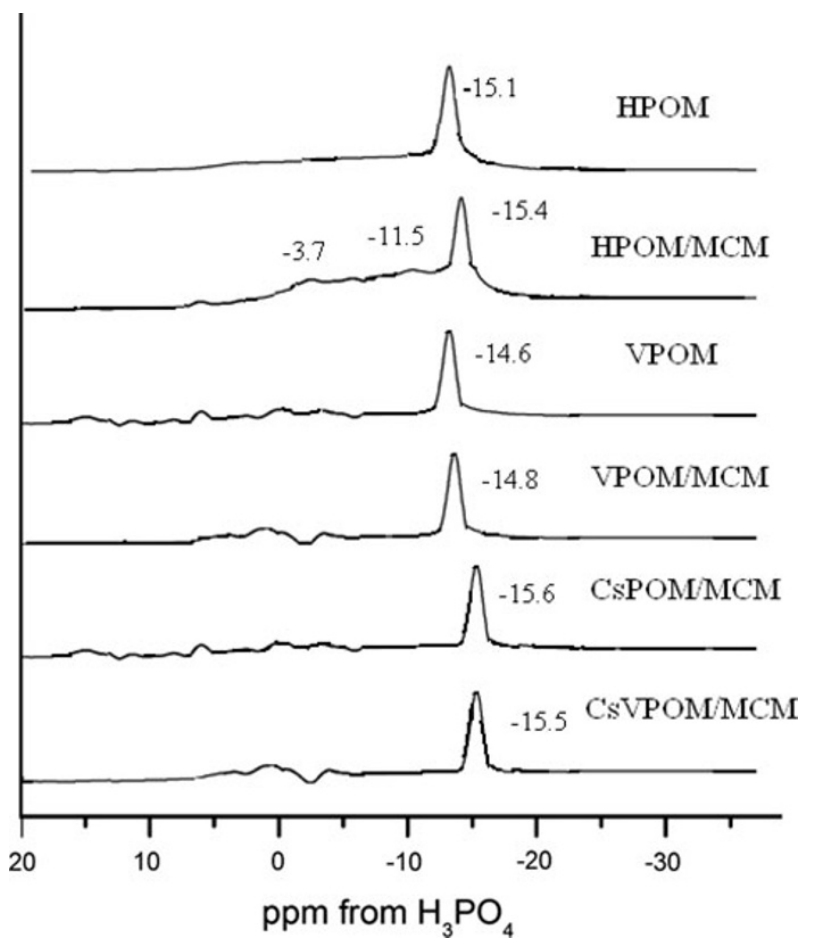

Fig. $7{ }^{31} \mathrm{P}\left\{{ }^{1} \mathrm{H}\right\}$ MAS NMR spectra of unsupported and supported catalysts 
from $\left(\mathrm{SiOH}_{2}\right)^{+}\left(\mathrm{H}_{2} \mathrm{PW}_{12} \mathrm{O}_{40}\right)^{-}$species previously reported [9]. In addition two small peaks at -11.7 and $3.1 \mathrm{ppm}$ are due to decomposition fragments (the HPOM/MCM sample was calcined at $350{ }^{\circ} \mathrm{C}$ ). For the VPOM and VPOM/MCM the resonance appears at -14.6 and $-14.8 \mathrm{ppm}$, respectively. Both the Cs-supported catalysts showed resonances at a little up-field shift (compared to the acid supported catalysts), -15.6 and $-15.5 \mathrm{ppm}$ for the CsPOM/MCM and CsVPOM/MCM, respectively, in agreement with the previous report [30]. No peak from decomposition fragment was detected, demonstrating their higher thermal stability than that of the HPOM/MCM.

The oxidation of cyclohexane was performed using $\mathrm{H}_{2} \mathrm{O}_{2}$ as oxidant in the presence and absence of catalyst. Blank reaction in the presence of MCM-41 did not show any products. The unsupported catalysts (CsPOM and CsVPOM) showed low conversion of cyclohexane. The catalytic activities of the supported catalysts were compared under the same reaction conditions and the results are presented in Table 2.

For the supported catalysts, HVPOM/MCM showed higher activity and selectivity to cyclohexanone than the

Table 2 Oxidation of cyclohexane $(0.4 \mathrm{~g}$ catalyst, substrate $92 \mathrm{mmol}, \mathrm{H}_{2} \mathrm{O}_{2} /$ cyclohexane molar ratio $=4$, reaction time $8 \mathrm{~h}$, temperature $80^{\circ} \mathrm{C}$ )

\begin{tabular}{|c|c|c|c|c|c|}
\hline \multirow[t]{2}{*}{ Catalyst } & \multicolumn{2}{|l|}{$\%$ POM } & \multirow[t]{2}{*}{$\begin{array}{l}\text { Conversion }{ }^{\mathrm{b}} \\
\text { (\%) }\end{array}$} & \multicolumn{2}{|c|}{$\begin{array}{l}\text { Selectivity }{ }^{\mathrm{c}} \\
(\%)\end{array}$} \\
\hline & Loaded & $\begin{array}{l}\text { After } \\
\text { reaction }^{\mathrm{a}}\end{array}$ & & -one & $-\mathrm{ol}$ \\
\hline MCM & - & - & 0 & - & - \\
\hline $\mathrm{CsPOM}^{\mathrm{d}}$ & - & - & 5 & 52 & 48 \\
\hline $\mathrm{CsVPOM}^{\mathrm{d}}$ & - & - & 9 & 58 & 42 \\
\hline HPOM/MCM & 20 & 13.1 & 14 & 66 & 34 \\
\hline $\begin{array}{l}\text { HVPOM/ } \\
\text { MCM }\end{array}$ & 20 & 13.5 & 18 & 70 & 30 \\
\hline \multirow[t]{3}{*}{ CsPOM/MCM } & 15 & 14.8 & 9 & 64 & 36 \\
\hline & 20 & 19.2 & 13 & 68 & 32 \\
\hline & $20^{\mathrm{e}}$ & 19.0 & 12 & 66 & 34 \\
\hline \multirow{3}{*}{$\begin{array}{l}\text { CsVPOM/ } \\
\text { MCM }\end{array}$} & 15 & 14.7 & 18 & 75 & 25 \\
\hline & 20 & 19.1 & 22 & 78 & 22 \\
\hline & $20^{\mathrm{e}}$ & 18.9 & 21 & 77 & 23 \\
\hline VPOM/MCM ${ }^{\mathrm{f}}$ & 16 & 15.0 & 19 & 76 & 24 \\
\hline
\end{tabular}

${ }^{\mathrm{a}}$ Deduced from the chemical analysis of $\mathrm{W}$ by ICP

${ }^{b}$ Based on the gas chromatographic peak areas

${ }^{c}$ Expressed as a percentage of the total products; - one = cyclohexanone, - ol = cyclohexanol

${ }^{d}$ With same mole of POM as in the $20 \%$ supported catalyst

e At the 4th run

f $\left(\mathrm{Bu}_{4} \mathrm{~N}\right)_{4} \mathrm{PVW}_{11} \mathrm{O}_{40}$ on MCM-41 under the same reaction condition [21]
HPOM/MCM under the same loading, 14 and $18 \%$ conversion, and 66 and $70 \%$ selectivity, respectively. The reduction potential of HVPOM was reported to be higher than that of the HPOM [31]. Correlation between reduction potential and oxidation activity of $\mathrm{H}_{n} \mathrm{PV}_{x} \mathrm{~W}_{12-x} \mathrm{O}_{40}$ $(x=0-3)$ was also reported [32]. The remaining $\mathrm{W}$ content in the catalyst after the oxidation reaction was analyzed by XRF. The leaching of POM was calculated by the difference of $\mathrm{W}$ content in the catalyst before and after the reaction. The acidic POMs showed leaching into water (from aq. $\mathrm{H}_{2} \mathrm{O}_{2}$ ) used in this work.

For the insoluble Cs salt supported on MCM-41, the experimental results show that the CsPOM/MCM and HPOM/MCM with the same loading (20\%) have comparable activity. This might be due to difference in the nature of acidity of both supported catalysts. The HPOM/MCM has high Brønsted acidity while the CsPOM/MCM has high Lewis acidity. It was reported in the literature that the HPOM/Cs-MCM-41 is more active than the HPOM/MCM41 for butane isomerization [30]. An advantage of using the Cs-supported catalysts is that there is no leaching of CsPOM from the support, demonstrating higher stability than the acidic catalysts. Higher selectivity to cyclohexanone was also obtained from the V-containing catalysts. This could be due to high redox property of $\mathrm{V}$ and the beneficial effect of redox metal $\mathrm{V}$ on the oxidation properties of heteropolyoxometallate compounds was already observed in other cases. It was reported that $\left[\mathrm{PVW}_{11} \mathrm{O}_{40}\right]^{4-}$ exhibited three reversible one-electron redox waves. The first wave is ascribed to the reduction of $\mathrm{V}^{5+}$ in the peripheral position, and the remaining two to the reduction of $\mathrm{W}^{6+}$ [33]. Another reason may be due to the surface of the MCM-41 support which can accumulate the produced cyclohexanol at the interfaces and, consequently, oxidized to cyclohexanone. The highest activity from the CsVPOM/ MCM obtained in this work might be because of combined effect of surface area, role of $\mathrm{V}$, Cs and acidity of the catalyst. The conversion obtained from this work is higher than that from our previous work over $\left(\mathrm{Bu}_{4} \mathrm{~N}\right)_{4} \mathrm{PVW}_{11} \mathrm{O}_{40} /$ MCM-41 [21] due to higher POM incorporated into the catalyst. The results of reusability show that there was a slight decrease in the activity of the CsPOM/MCM and CsVPOM/MCM at the 4th run (1\% drop).

When triphenylphosphine was added to the reaction products the GC analysis of this showed a sharp increase in the concentration of cyclohexanol, while the concentration of cyclohexanone substantially reduced. This proves that cyclohexane oxidation proceeds via the cyclohexyl hydroperoxide (intermediate) formation, which is found to be reduced by $\mathrm{PPh}_{3}$. Addition of 2,6-di-tert-butyl-4-methylphenol, a radical scavenger into the reaction resulted in no product, showing that oxidation appears to be a radical process [5]. 


\section{Conclusions}

In this study polyoxometalate supported MCM-41 was found to be an efficient catalyst for the oxidation of cyclohexane in the absence of added solvent using $\mathrm{H}_{2} \mathrm{O}_{2}$ as oxidant. Supported catalysts give higher cyclohexane conversion and cyclohexanone selectivity compared to bulk polyoxometalates. The advantage is easy separation and recycling.

Open Access This article is distributed under the terms of the Creative Commons Attribution License which permits any use, distribution, and reproduction in any medium, provided the original author(s) and the source are credited.

\section{References}

1. Shylesh S, Prinson PS, Singh A (2007) Chromium-containing small pore mesoporous silicas: synthesis, characterization and catalytic behavior in the liquid phase oxidation of cyclohexane. Appl Catal A 318:128

2. Nezhadali A, Akbarpour M (2010) Selective oxidation of primary substituted aromatic amines to azoxy products using lacunary catalyses. Chinese Chem Lett 21:43

3. Kozhevnikov IV (1998) Catalysis by heteropoly acids and multicomponent polyoxometalates in liquid-phase reactions. Chem Rev 98:171

4. Mizuno N, Misono M (1998) Heterogeneous catalysis. Chem Rev 98:199

5. Simoes MMQ, Santos ICMS, Balula MSS et al (2004) Oxidation of cycloalkanes with hydrogen peroxide in the presence of Keggin-type polyoxotungstates. Catal Today 211:91-92

6. Santos ICMS, Gamelas JAF, Balula MSS et al (2007) Sandwichtype tungstophosphates in the catalytic oxidation of cycloalkanes with hydrogen peroxide. J Mol Catal A Chem 262:41

7. Kozhevnikov IV, Sinnema A, Janse RJJ, Pamin K, van Bekkum $\mathrm{H}$ (1994) New acid catalyst comprising heteropoly acid on a mesoporous molecular sieve MCM-41. Catal Lett 30:241

8. Ajaikumar S, Pandurangan A (2008) HPW and supported HPW catalyzed condensation of aromatic aldehydes with aniline: synthesis of DATPM derivatives. J Mol Catal 286:21

9. Blasco T, Corma A, Mart'inez A, Martinez-Escolano P (1998) Supported heteropolyacid (HPW) catalysts for the continuous alkylationof isobutane with 2-butene: the benefit of using MCM41 with larger pore diameters. J Catal 177:306

10. Khder ARS, Hassan HMA, El-Shall MS (2012) Acid catalyzed organic transformations by heteropoly tungstophosphoric acid supported on MCM-41. Appl Catal A Gen 77:411-412

11. Kozhevnikov IV, Kloetstra KR, Sinnema A et al (1996) Study of catalysts comprising heteropoly acid $\mathrm{H}_{3} \mathrm{PW}_{12} \mathrm{O}_{40}$ supported on MCM-41 molecular sieve and amorphous silica. J Mol Catal A Gen 114:287

12. Sakthivel A, Selvam P (2002) Mesoporous (Cr)MCM-41: a mild and efficient heterogeneous catalyst for selective oxidation of cyclohexane. J Catal 211:134

13. Yao W, Chen Y, Min L et al (2006) Liquid oxidation of cyclohexane to cyclohexanol over cerium-doped MCM-41. J Mol Catal A Chem 246:162

14. Li J, Shi Y, Xu L et al (2010) Selective oxidation of cyclohexane over transition-metal-incorporated HMS in a solvent-free system. Ind Eng Chem Res 49:5392
15. Okuhara T, Watanabe H, Nishimura $\mathrm{T}$ et al (2000) Microstructure of cesium hydrogen salts of 12-tungstophosphoric acid Relevant to novel acid catalysis. Chem Mater 12:2230

16. Izumi Y (1997) Hydration/hydrolysis by solid acids. Catal Today 33:371

17. Dias AS, Lima S, Pillinger M (2006) Acidic cesium salts of 12-tungstophosphoric acid as catalysts for the dehydration of xylose into furfural. Carbohydr Res 341:2946

18. Tangestaninejad S, Mirkhani V, Moghadam M et al (2008) Hydrocarbon oxidation catalyzed by vanadium polyoxometalate supported on mesoporous MCM-41 under ultrasonic irradiation. Ultrason Sonochem 15(4):438

19. Serwicka EM, Broclawik E, Bruckman K, Haber J (1989) TPD/ TPR and quantum chemical study of methanol interaction with $\mathrm{H}_{3+n} \mathrm{PV}_{n} \mathrm{Mo}_{12-n} \mathrm{O}_{40}$ heteropolyacids. Catal Lett 2:351

20. Wang J, Hu C, Jian M et al (2006) Catalytic oxidation performance of the $\alpha$-Keggin-type vanadium-substituted heteropolymolybdates: a density functional theory study on $\left[\mathrm{PV}_{\mathrm{n}} \mathrm{Mo}_{12-\mathrm{n}} \mathrm{O}_{40}\right]^{(3+\mathrm{n})-}$ $(\mathrm{n}=0-3)$. J Catal 240:23

21. Jatupisarnpong J, Trakarnpruk W (2012) Transition metalsubstituted polyoxometalates loaded MCM- 41 as catalysts in the oxidation of cyclohexane and cyclooctane with $\mathrm{H}_{2} \mathrm{O}_{2}$. Mendeleev Commun 22:152

22. Zhang C, Zhou W, Liu S (2005) Synthesis and characterization of organofunctionalized MCM-41 by the original stepped templated sol-gel technology. J Phys Chem B 109(51):24319

23. Park DR, Song SH, Hong UG et al (2009) Redox properties and catalytic oxidation activities of polyatom-substituted $\mathrm{H}_{\mathrm{n}} \mathrm{PW}_{11}$ $\mathrm{M}_{1} \mathrm{O}_{40}(\mathrm{M}=\mathrm{V}, \mathrm{Nb}, \mathrm{Ta}$, and $\mathrm{W})$ Keggin heteropolyacid. Catalysts Catal Lett 132:363

24. Okuhara T, Nishimura T, Watanabe H et al (1992) Insoluble heteropoly compounds as highly active catalysts for liquid-phase reactions. J Mol Catal 74:247

25. Soled S, Miseo S, McVicker G et al (1997) Preparation of bulk and supported heteropolyacid salts. Catal Today 36:441

26. Rafiee E, Nejad FK, Joshaghani M (2011) $\mathrm{Cs}_{x} \mathrm{H}_{3-x} \mathrm{PW}_{12} \mathrm{O}_{40}$ heteropoly salts catalyzed quinoline synthesis via Friedländer reaction. Chinese Chem Lett 22:288

27. Parida KM, Rana S, Mallick S, Rath D (2010) Cesium salts of heteropoly acid immobilized mesoporous silica: an efficient catalyst for acylation of anisole. J Colloid Interf Sci 350:132

28. Karthikeyana G, Pandurangan A (2009) Heteropolyacid $\left(\mathrm{H}_{3} \mathrm{PW}_{12} \mathrm{O}_{40}\right)$ supported MCM-41: an efficient solid acid catalyst for the green synthesis of xanthenedione derivatives. J MolCatal A Chem 311:36

29. Alsalme AM, Wiper PV, Khimyak YZ, Kozhevnikova EF, Kozhevnikov IV (2010) Solid acid catalysts based on $\mathrm{H}_{3} \mathrm{PW}_{12} \mathrm{O}_{40}$ heteropoly acid: acid and catalytic properties at a gas-solid interface. J Catal 276:181

30. Yang W, Billy J, Ben Taarit Y, Védrine JC, Essayem N (2002) $\mathrm{H}_{3} \mathrm{PW}_{12} \mathrm{O}_{40}$ supported on $\mathrm{Cs}$ modified mesoporous silica: catalytic activity in $n$-butane isomerisation and in situ FTIR study. Comparison with microporous $\mathrm{Cs}_{x} \mathrm{H}_{3-x} \mathrm{PW}_{12} \mathrm{O}_{40}$. Cat Today $73: 153$

31. Song IK, Barteau MA (2004) Redox properties of Keggin-type heteropolyacid (HPA) catalysts: effect of counter-cation, heteroatom, and polyatom substitution. J Mol Catal A Chem 212:229

32. Park DR, Park S, Bang Y (2010) Reduction potential, UV-visible absorption edge energy, and oxidation catalysis of niobium-containing $\mathrm{H}_{3+x} \mathrm{PW}_{12-x} \mathrm{Nb}_{x} \mathrm{O}_{40}$ Keggin and $\mathrm{H}_{6+x} \mathrm{P}_{2} \mathrm{~W}_{18-x} \mathrm{Nb}_{x} \mathrm{O}_{62}$ Wells-Dawson heteropolyacid catalysts. Appl Catal A Gen 373:201

33. Himeno S, Takamoto M, Higuchi A et al (2003) Preparation and voltammetric characterization of Keggin-type tungstovanadate $\left[\mathrm{VW}_{12} \mathrm{O}^{40] 3-}\right.$ and $\left[\mathrm{V}\left(\mathrm{VW}_{11}\right) \mathrm{O}_{40}\right]^{4-}$ complexes. Inorg Chim Acta 348:57 